\title{
CONTRIBUIÇÕES DA TEORIA DO APEGO NO CONTEXTO ESCOLAR
}

\section{ARTIGO ORIGINAL}

SASSI, Franciele ${ }^{1}$

MONTORO, Fernanda Castanho Franco ${ }^{2}$

BARIVIERA, Juliana ${ }^{3}$

BRESCIA, Silvia Ribeiro ${ }^{4}$

SASSI, Franciele. Et Al. Contribuições da teoria do apego no contexto escolar. Revista Científica Multidisciplinar Núcleo do Conhecimento. Ano 03, Ed. 10, Vol. 06, pp. 05-28 Outubro de 2018. ISSN:2448-0959

\section{RESUMO}

O modelo pedagógico predominante na contemporaneidade parece ter encoberto, durante um largo período de tempo, a expressão da afetividade nas relações entre professor $x$ aluno, uma vez que 0 ideal de relacionamento entre as hierarquias

\footnotetext{
${ }^{1}$ Bacharel em Psicologia pela Universidade de Caxias do Sul, Especialista em Teoria, Pesquisa e Intervenção em Luto, Especialista em Prevenção e Tratamento de Dinâmicas Vinculares pela Teoria do Apego, ambas pelo Quatro Estações Instituto de Psicologia.

2 Graduação em Psicologia pela Pontifícia Universidade Católica de São Paulo, especialista em Psicanálise da Criança pelo Instituto Sedes Sapientiae e especialista em Teoria do Apego pelo Quatro Estações Instituto de Psicologia.

${ }^{3}$ Graduação em Psicologia pela Faculdade da Serra Gaúcha. Especializanda em Teoria do Apego pelo Quatro Estações Instituto de Psicologia.

${ }^{4}$ Graduação em Psicologia com formação de analistas pela Sociedade Brasileira de Psicologia Analítica, especialista em Teoria do Apego pelo Quatro Estações Intituto de Psicologia.
} 
postulava a transmissão do saber como principal objetivo do ensino, o que era atravessado pelo distanciamento entre o mestre e o aluno. Todavia, quando se analisam as necessidades de formação dos professores, levando em conta os efeitos do primeiro contato destes com a realidade das crianças por eles atendidas, verifica-se que este é um domínio relevante e referenciado. É fundamental analisar a questão da afetividade em sala de aula, trabalhando sob possibilidades de estímulo de vinculação pelo viés da psicoeducação, levando em conta as condições de ensino operacionalizadas pelo professor. O presente trabalho, portanto, propõe-se a criar uma metodologia de intervenção, numa proposta de formação de professores por meio da elaboração, passo-a-passo, de um workshop teórico-vivencial, visando sua sensibilização e instrumentalização, para que o professor perceba o ingresso da criança na escola como uma experiência e um espaço seguros, para além do mundo familiar, e que oportunize formas de entender a si mesma e o mundo de forma mais autônoma. E que o professor, enquanto figura extensa de referência, possa atuar como mediador seguro no desenvolvimento de novas interações afetivas, cognitivas e sociais para a criança.

Palavras-chave: relacionamento, professor $x$ aluno, vínculo afetivo na escola, teoria do apego e educação.

\section{INTRODUÇÃO}

As observações sobre os efeitos do distanciamento e/ou separação das crianças com seus principais cuidadores na primeira infância, fizeram com que o psiquiatra, especialista em psiquiatria infantil e psicanalista inglês John Bowlby iniciasse seus estudos e dessa origem à Teoria do Apego. Seus conceitos baseiam-se em diferentes perspectivas, como a psicanálise, biologia evolucionária, etologia, psicologia do desenvolvimento, ciências cognitivas e sistemas de controle (Bowlby, 1989). Seus trabalhos comprovaram que o modelo de apego que o indivíduo desenvolve na primeira infância se refere à maneira como os cuidadores primários o tratam, como também estão ligados a fatores temperamentais e genéticos (Dalbem \& Dell'aglio, 2005). De acordo com Bowlby (1989), cada indivíduo forma seus modelos operativos internos com base nas primeiras experiências com a figura de apego. Assim, a criança 
desenvolve modelos operativos internos de si mesma, do outro e do mundo, de acordo com a forma como foi cuidada, e isso servirá de base para os seus relacionamentos futuros. Na medida em que este modelo for seguro, isto vai auxiliá-la a acreditar em si própria, desenvolver sua independência e explorar as relações e o mundo com segurança. No entanto, quando as figuras de referência mostram-se inseguras, ansiosas e não atendem ou não são empáticas às necessidades da criança, esta tende a desenvolver um estilo de apego inseguro ambivalente ou evitativo, em que, no primeiro, apresenta-se temerosa à separação de sua figura de apego e, consequentemente, a exploração do mundo se torna comprometida, ou, no segundo, em que a criança mostra-se aparentemente indiferente aos efeitos do distanciamento do adulto cuidador, porém, apresenta sintomas de outra ordem. Há também o estilo de apego desorganizado, em que a criança demonstra uma dinâmica oscilante entre a ambivalência e a evitação. Geralmente, são crianças contraditórias na manifestação do comportamento diante da figura de referência (Casellato, 2012).

Entende-se, portanto, que a forma como a criança se percebe e entende o mundo está relacionada à interação que teve com sua mãe ou figura substituta (Bowlby, 1989). A partir da modalidade relacional estabelecida entre o "eu", o "outro" e o "mundo", a criança buscará novas figuras de referência que possam assegurar-Ihe no contexto externo. A escola, por exemplo, constitui uma das primeiras experiências de mundo externo que a criança vivencia posteriormente à sua relação com os cuidadores primários. É a partir da experiência escolar que a criança estende sua rede de cuidadores e também desenvolve uma rede de apoio baseada nas amizades que formará. Os professores, como representantes da ampliação do mundo da criança, compõem parte fundamental na estruturação, flexibilização e consolidação de laços afetivos seguros e contínuos para esta, entendendo que um vínculo seguro promove autoconfiança e contribui para o seu êxito na vida escolar e enquanto adulto (Amado et. al., 2009). Entende-se, desta forma, que as opiniões e condutas dos pais e, posteriormente, dos professores consistem em importantes fatores para a criança, auxiliando-as na construção do seu self. Do contrário, se a informação recebida for negativa, a criança também passará a aprender e se perceber diante das relações e do mundo da mesma maneira (Freddo, 2004). 
Entendendo a importância da vinculação segura entre cuidadores e crianças desde o início do desenvolvimento, o presente trabalho tem por objetivo promover uma instrumentalização reflexiva e prática direcionada a professores, a fim de possibilitar caminhos para que se estabeleça uma relação segura entre estes e seus alunos em início de período escolar, contribuindo para a relação ensino-aprendizagem. A proposta interventiva está relacionada a momentos específicos de trabalho com professores, realizados pela equipe contratada mediante conteúdos teóricos que fundamentam a prática, além de vivências de imersão que desenvolvam e aprimorem possibilidades de relações seguras e funcionais no ambiente escolar, garantindo a qualidade do ensino. Entende-se que o investimento em práticas de relação afetiva estabelecida com o professor, como figura de apego extensa aos pais, composta pelo primeiro contato com o mundo externo da criança, é fundamental, uma vez que o professor pode ser capaz de solidificar e construir laços de confiança com o aluno para a exploração e conhecimento deste de forma eficiente e eficaz (Amado et. al., 2009).

Estudos na área da educação realizados por Wallom (1968) e Vygotsy (1998) têm mostrado que é por intermédio da afetividade relacional que o indivíduo acessa os sistemas simbólico-culturais, "originando a actividade cognitiva e possibilitando o seu avanço, pois são os desejos, intenções e motivos que vão mobilizar a criança na selecção de actividades e objectos" (Leite \& Tagliaferro, 2005, p. 50). Logo, os processos cognitivos e afetivos estão mutuamente inter relacionados e sofrem influência entre si. O conceito de zona de desenvolvimento proximal, por exemplo, apresentado por Vygotsky (1998), refere que relações concretas entre pessoas estão associadas ao desenvolvimento das funções superiores, o que torna fundamental a ajuda e o apoio promovidos pelo professor se pensado no contexto da sala de aula com seus alunos. Além disso, as investigações no campo das neurociências têm demonstrado que sentimentos e consciência não são estranhos e separados, exercendo intenso impacto no processo ensino-aprendizagem (Damásio, 2000 em Amado et. al., 2009). Sugere-se, ainda, que o cérebro humano precisa de um certo desafio para ativar emoções e aprendizagem de forma concomitante, e que um ambiente físico seguro é particularmente importante na redução de níveis acentuados 
de estresse, nocivos ao bem-estar do indivíduo e à aprendizagem (Muijs \& Reynolds, 2005,em Amado et. al, 2009).

No que tange à educação moral e socialização, a escola também tem importante papel, visto que é neste espaço que a criança convive com os pares fora do ambiente familiar. Estudos de educação moral construtivista (Piaget, 1996; Araújo, 1996) ressaltam a importância da relação professor x aluno e dos alunos entre si - relação esta que também é orientada pelas práticas do professor - na construção de uma moral autônoma, baseada em respeito, reciprocidade e cooperação. Para Piaget, 1996 (apud De La Taille), não é somente a maturação biológica que explica o desenvolvimento, mas as múltiplas interações que ocorrem com o meio físico e social. $\mathrm{Na}$ moral heterônoma (Piaget, 1996), a aceitação das regras acontece de forma unilateral, uma vez que a criança obedece, porque foi orientada pelo adulto, e isto constitui parte do processo de desenvolvimento infantil. Contudo, esta não pode ser a única forma de educação moral, dado que leva à substituição do respeito pelo medo, da cooperação pela coação. Desta forma, as relações unilaterais baseadas no autoritarismo e no medo da punição inibem o sistema exploratório da criança, prejudicando o desenvolvimento cognitivo, social e moral (Piaget, 1996).

A função do educador deve ser repensada para além da transmissão de conteúdos didáticos, uma vez que exerce o papel de cuidador alternativo na construção de uma base segura para a criança e se refere a um modelo para ser seguido pelo aluno (Casellato 2012). Isto posto, parece haver uma acentuada relação entre a aprendizagem do aluno e a qualidade da relação educador-criança no que tange à segurança e ao conforto emocional, sobretudo em etapas mais precoces da escolaridade, as quais envolvem disponibilidade afetiva e asseguramento íntegro para a exploração do ambiente (Pianta et al., 1995, em Amado et. al., 2009).

As crianças freqüentam escolas por um período muito longo de suas vidas, assim estabelecem relacionamentos de longo prazo com adultos. Isso oferece oportunidade para que elas experimentem a si mesmas de maneira mais positiva e vivenciem o aprendizado. A partir disso, adquirem um senso de gerenciamento e envolvimento com um grupo social; um ensaio para a vida futura. Para muitas crianças, a escola é 
o caminho de acesso para a realização e pode compensar em algum grau as ausências nas primeiras experiências que inibem 0 desenvolvimento e a aprendizagem. Assim, é útil refletir sobre as possibilidades de melhorar as capacidades das escolas como Base Segura. (Geddes, 2006)

Ressalta-se a importância do auxílio de profissionais capacitados - psicólogos e psicopedagogos - que possam orientar de forma preventiva e global os educadores acerca das funções que possuem no desenvolvimento emocional e integral das crianças no contexto escolar, bem como alertá-los sobre as condições de proteção e risco no desenvolvimento e inserção dos alunos em sociedade. Além disso, disponibilizar meios que favoreçam a compreensão dos papéis da escola na promoção de segurança das crianças e adolescentes, de forma complementar ao papel da família (Casellato, 2012).

$\mathrm{Na}$ vida das crianças, o ambiente familiar é a principal âncora, o porto seguro de onde saem para explorar um mundo fora de casa e fazer novas descobertas a partir do que foi aprendido. A escola, sendo o primeiro espaço externo para a exploração, apresenta uma função importante ao permitir que a criança saia de seu núcleo familiar, considerada a matriz de sua identidade, e possa ser inserida na cultura. A partir do conhecimento do mundo, a criança vai formando sua própria identidade.

A escola é o lugar propício para as crianças, por meio do contato com seus pares e da relação com outros adultos, experimentarem e desenvolverem sua capacidade de socialização, a percepção sobre si, do outro e o reconhecimento dos seus próprios limites. No ambiente escolar, as crianças aprendem a conviver e trabalhar em grupos, compreender e respeitar as regras, explorar e descobrir um mundo fora de sua casa. Estas tarefas vêm, inevitavelmente, acompanhadas de conflitos e angústias tanto por parte da família como por parte dos filhos, em razão de constituir uma nova experiência de distanciamento das figuras de referência seguras. Contudo, na medida em que as crianças dispõem de recursos internos, desenvolvidos nos meios os quais vivem e aprimorados pelas interações feitas, acabam encontrando um ambiente afetivamente estável, e esses conflitos vão sendo superados e elaborados. 
O presente trabalho, portanto, propõe-se a criar uma metodologia de intervenção com base em uma espécie de workshop, na proposta de formação de professores, visando sua sensibilização e instrumentalização, para que o ingresso da criança na escola seja uma experiência e um espaço seguros, para além do mundo familiar, e que oportunize formas de perceber a si mesma e o mundo de forma mais autônoma. E que o professor, enquanto figura extensa de referência, possa atuar como mediador seguro no desenvolvimento de novas interações afetivas, cognitivas e sociais para a criança.

Considera-se a instituição escolar como potencial fonte de bem estar emocional e de resiliência. Uma criança com uma experiência de apego predominantemente inseguro, por exemplo, ao estabelecer relações com outros cuidadores significativos, pode vivenciar experiências positivas e assim melhorar sua autoestima e resiliência. (Geddes, 2006)

Segundo os Parâmetros Curriculares Nacionais, documento produzido em 1997 pelo Ministério da Educação, que orienta e regulariza a prática pedagógica no país, além de uma formação inicial consistente, é preciso considerar um investimento educativo contínuo e sistemático para que o professor se desenvolva como profissional de educação. O conteúdo e a metodologia para as formações precisam ser revistos, a fim de que haja a possibilidade de melhoria do ensino. A formação, neste sentido, não pode ser tratada como um acúmulo de cursos e técnicas, mas como um processo reflexivo e crítico sobre a prática educativa (Ministério da Educação, 1997).

O modelo pedagógico predominante na contemporaneidade parece ter encoberto, durante um largo período de tempo, a expressão da afetividade nas relações entre professor $x$ aluno, uma vez que o ideal de relacionamento entre as hierarquias postulava a transmissão do saber como principal objetivo do ensino, o que era atravessado pelo distanciamento entre o mestre e o aluno. Apesar do impacto lento e progressivo de outros modelos pedagógicos que buscavam ceder um lugar de importância para o papel da afetividade e da sua expressão na relação pedagógica, as investigações não obtiveram êxito quanto ao seu estudo. Portanto, tem sido ofertado reduzido espaço a esta dimensão da atividade docente, quer na formação inicial quer nas modalidades de formação continuada (Amado et. al., 2009). Os 
autores defendem que, na formação inicial, a problemática da relação pedagógica é pouco abordada e feita de forma dispersa, assistemática e pouco fundamentada (Amado et. al., 2009). Todavia, quando se analisam as necessidades de formação dos professores, levando em conta os efeitos do primeiro contato destes com a realidade das crianças por eles atendidas, verifica-se que este é um domínio relevante e referenciado. Destaca-se que há uma quantidade significativa de educadores que, ao longo de sua experiência profissional, não consegue atravessar as dificuldades encontradas no campo relacional, o que reflete negativamente no desempenho escolar dos alunos, no bem-estar de ambos e na realização profissional dos professores (Amado et. al., 2009). Os professores refletem sobre sua prática, buscando explicações fora dela (políticas públicas, filosofia pedagógica da escola, planejamento, estrutura física, recursos materiais, metodologias de ensino, teorias, etc.) e o professor resiste ao convite de refletir e conhecer o seu comportamento e a qualidade das relações que ele estabelece com o aluno (Parolin e Küster, 2010). Ainda permanece no imaginário cultural a ideia de que escola é lugar de estudar, e que manifestações emocionais não cabem na sala de aula (Parolin e Küster, 2010). Portanto, cabe construir conhecimento acerca desta realidade, fornecendo os quadros de referência e as orientações metodológicas que adequem esta dimensão da formação profissional dos professores e da sua prática diária. Para além de outras dimensões da relação pedagógica que envolvem conhecimento técnico e sistemático, parece necessário e importante promover propostas para reflexão e compreensão em torno da dimensão afetiva da vida dos professores, dos alunos e da interação entre ambos (Amado et. al., 2009).

A relação pedagógica consiste, dentre outros fatores, no contato interpessoal que se estabelece num determinado espaço e tempo delimitado, num processo de ensino-aprendizagem entre professor-aluno-turma (Estrela, 2002). A qualidade dessas relações e os efeitos sobre cada um dos envolvidos dependem de múltiplos fatores, como a subjetividade de cada um, as interpretações individuais e compartilhadas em torno das situações e vivências da aula e da escola, os trajetos de vida e os projetos pessoais. É esta combinação de individualidades que torna fundamental a exigência de uma ética que mantenha o professor alerta para a sua 
responsabilidade como mediador na construção das relações afetivo-emocionais do aluno, enquanto responsável pelas dimensões cognitiva, moral e relacional. Uma responsabilidade que se estende para além da construção de cada trajetória particular e que atinge a sociedade e o futuro (Amado, et al, 2009).

Se, por um lado, as aprendizagens escolares dependem de um conjunto de exigências de ordem técnica, uma vez que o avanço nos conhecimentos e novas tecnologias garantem e exigem, não se pode deixar de considerar que, por outro viés, o conjunto de características afetivas disponibilizadas na relação professor $x$ aluno possibilita que os conteúdos mobilizem este último e ative "os mecanismos cognitivos para trabalhar a informação e para que a aprendizagem significativa se efectue" (Gonçalves \& Alarcão, 2004, p. 6 em Amado et. al., 2009). É fundamental analisar a questão da afetividade em sala de aula, trabalhando sob possibilidades de estímulo de vinculação pelo viés da psicoeducação, tendo em conta as condições de ensino operacionalizadas pelo professor. Analisar a questão na perspectiva da relação do professor para com os alunos implica dar conta do modo como estes percebem a ação daquele no domínio do respeito, no plano da competência, da justiça relacional e da gestão dos poderes, e no plano pessoal, entendendo a abertura aos interesses e problemas do aluno, cuidado e preocupação, valorização da sua liberdade e sentimentos (Amado et. al., 2009).

\section{CONTRIBUIÇÕES DA TEORIA DO APEGO NA CONSTRUÇÃO DOS VÍNCULOS AFETIVOS}

Todo ser humano nasce com a propensão para formar vínculos afetivos. Perspectivas referentes à vasta história da evolução da humanidade consideram o homem na matriz de suas relações interpessoais, sendo este, portanto, de natureza relacional e caracterizado pelo estabelecimento de intensos, contínuos e recíprocos laços com seus pares, a fim de assegurar o reconhecimento de si, do outro, do pertencimento na relação, garantindo a sobrevivência da espécie (Yalom \& Leszcz, 2005). O recémnascido, desde o início, é ativo na busca de cuidados e irá nomear uma figura 
considerada por ele especial, ao qual desenvolverá comportamentos de apego, a fim de assegurar seu desenvolvimento biopsicoafetivo (Rosa et. al., 2010).

O vínculo afetivo se refere a um laço duradouro que se estabelece com um indivíduo. O apego promove uma disposição a buscar proximidade e contato com a figura de apego escolhida, com o objetivo de obter proteção e segurança. A criança vai desenvolvendo comportamentos de apego para conseguir ter e manter a proximidade com sua figura de referência como, por exemplo, chorar, balbuciar, gritar, sorrir, agarrar-se. $O$ estilo de apego que irá se desenvolver depende da interação entre o adulto cuidador e a criança, em que a saúde mental desta última dependerá de que ambos possam encontrar satisfação e prazer na relação. Um apego seguro se estabelece quando um adulto consegue ser continente e sensível, respondendo às necessidades da criança e autorizando a exploração, validando suas conquistas (Ribas \& Moura, 2004).

O comportamento da criança na escola, assim como o seu aprendizado no contexto de base, pode vir a ser o resultado da interação junto ao professor. A dinamicidade da relação também corresponde com as características vinculares que ela desenvolveu com seus pais ou cuidadores anteriormente. Deste modo, entende-se que os professores contribuem para as formas que a criança passará a entender a si mesma, as pessoas e o mundo. Na medida em que se estabelece uma vinculação segura na base familiar, internalizada na relação do "eu" com o "outro" - continuada através da escola, no vínculo com o professor enquanto cuidador representante - isto contribui para que a criança tenha uma base mais assegurada em relação ao mundo externo, oportunizando maior autonomia (Freddo, 2004). Do contrário, o comportamento disfuncional demonstrado na escola, bem como dificuldades de aprendizagem, sentimentos de incapacidade ou inferioridade por parte da criança, uma visão distorcida de si mesmo e do mundo, podem ser fatores relacionados à falta de interação positiva e segura da criança com suas figuras primárias de cuidado (Bowlby, 1989). A insegurança se reflete na escola como contexto de expressão do sintoma, possivelmente causando dificuldades de adaptação, aprendizagem e de interação (Freddo, 2004). 


\section{RELAÇÃO PROFESSOR X ALUNO E SUAS IMPLICAÇÕES NO PROCESSO ENSINO X APRENDIZAGEM}

Os professores são figuras importantes para o desenvolvimento saudável e funcional da criança, pois a qualidade dos vínculos pode influenciar nos modelos sobre como esta percebe a si mesma, o outro e o mundo, interferindo, como efeito, no seu processo de aprendizagem e autoconhecimento. Assim, experiências positivas ou negativas no ambiente escolar, desencadeadas pela conduta do professor, poderão intervir na construção da imagem que a criança irá adquirir sobre si mesma e suas possíveis capacidades (Ferraz \& Ristum, 2012).

Em 1927, em comemoração ao 50 aniversário de fundação do colégio onde estudou dos 9 aos 17 anos, Freud (1913/1914 ) escreveu um artigo intitulado "Algumas Reflexões sobre Psicologia Escolar", no qual destaca a importância da personalidade dos mestres na formação e interesse dos alunos. O autor (Freud, 1913/1914) descreve os sentimentos ambivalentes dos alunos em relação aos professores e postula que estes tornam-se figuras substitutas e representam imagos das principais figuras afetivas das crianças (pai, mãe, irmãos). Ressalta a importância das primeiras relações nos processos emocionais dos indivíduos e como levamos essa herança emocional para as próximas relações. Diz, ainda, que é possível trabalhar para transformar alguns padrões emocionais em certas direções, mas que não se pode jamais livrar-se do impacto das primeiras experiências (Freud, 1913/1914). Os professores como figuras substitutas, na linguagem de Freud, ou figuras de apego subsidiárias, a partir de Bowlby, recebem a herança emocional e têm papel fundamental no desenvolvimento pedagógico, emocional e social dos alunos. Atuam como referência para os educandos, então, a forma como ele se relaciona com seus alunos implica diretamente no processo de aprendizagem e é essencial para que se sintam seres capazes e seguros (Belotti \& Faria, 2010). É o vínculo afetivo, ou seja, a base de uma relação vincular segura entre aluno e professor que corrobora com a construção do processo inicial da aprendizagem (Tassoni, 2000). 
Toda aprendizagem envolve afetividade, que ocorre a partir de interações sociais em um processo vincular. Portanto, as maneiras como o professor irá se vincular com os alunos e conduzir seus ensinamentos implicarão diretamente no percurso da aprendizagem. É importante que o professor consiga interagir com seu aluno, com base em uma relação segura, de confiança, a qual possa acolher, validar, compreender e aceitar a individualidade dos alunos (Tassoni, 2000). Entende-se que o papel do educador em sala de aula tem sofrido alterações nos últimos anos, ou seja, não mais é necessário que o professor seja visto exclusivamente como figura de autoridade, bastando apenas saber e transmitir conhecimentos, mas as mudanças de mundo demandam que o novo professor possa interagir, discutir, dar voz e vez ao aluno, proporcionando um espaço seguro, com uma postura flexível e compreensiva para que a turma como um todo seja capaz de expressar seus sentimentos e sentir acolhimento (Belotti \& Faria, 2010).

\section{A ESCOLA COMO REFERÊNCIA SEGURA DE CUIDADOS}

Nas escolas mais antigas, a questão ensino-aprendizagem era centrada somente no professor. O conhecimento precisava ser transmitido para o aluno independentemente de suas necessidades. Atualmente, a Lei de Diretrizes e Bases da Educação Nacional descreve as mudanças que as escolas precisam adquirir, já que o conhecimento é uma construção contínua. A escola precisa corroborar com a construção pessoal de cada um e contribuir para que o aluno não tenha de seu professor apenas o conteúdo transmitido, mas que possa aprender a se sentir seguro e confiante em suas capacidades (Belotti \& Faria, 2010).

Um dos objetivos da escola deve ser o de integrar os indivíduos na sociedade, sendo assim, é necessário que o professor consiga incluir em seu processo de ensinoaprendizagem a realidade e necessidades de cada um. Esse conhecimento auxilia nos interesses, dificuldades, facilidades e o contexto cultural que envolve cada aluno e que estão diretamente ligados às formas de aprender (Belotti \& Faria, 2010).

A escola é um dos primeiros agentes socializadores externo ao contexto familiar. Torna-se a base de aprendizagem na medida em que proporciona um espaço para 
que a criança se sinta segura e protegida. Desta forma, a fim de que a criança tenha um desenvolvimento saudável funcional nos contextos escolar e social, torna-se imprescindível que as relações interpessoais sejam positivas, seguras, de apoio e aceitação (Krueger, 2003).

As escolas são fontes significativas de saúde na comunidade. A maioria delas demonstram uma preocupação e cuidado para com as crianças, que é uma experiência substancial para várias delas, cujas necessidades emocionais e sociais não são atendidas nem pela família nem pelo meio ambiente. (Geddes, 2006)

A criança necessita ser amada, compreendida, aceita em suas individualidades, respeitada, acolhida e ouvida, para que possa ser estimulada a entrar no mundo do aprendizado. Uma vez que desenvolve suas experiências através da vivência com o outro, se o professor demonstrar atenção, cuidado, afeto, manter diálogo, orientar, acolher, o aluno poderá sentir segurança e proteção. Os métodos de ensino da escola e os professores como seus representantes desempenham um papel importante para o desenvolvimento da criança. São fundamentais não apenas na evolução do processo de aprendizado, mas também para incentivar o fortalecimento da autoconfiança e autoestima (Krueger, 2003).

Neste sentido, o processo de aprendizagem deve ser bem acompanhado e compreendido. Percebe-se muitas vezes que a dificuldade de aprendizagem tem relação direta com comportamentos da criança. A dificuldade de aprendizagem pode ser compreendida como um sintoma das preocupações e experiências da criança. (Geddes, 2006)

Quando buscamos compreender o significado do comportamento e torná-lo explícito, ocorre a liberação do bloqueio da aprendizagem, possibilitando o progresso. Muitos comportamentos que as crianças trazem para a escola refletem esperanças inconscientes de que alguém entenderá suas necessidades e compreenderá sua comunicação. (Geddes, 2006) 


\section{IMPLICAÇÕES DA NEUROPLASTICIDADE EM RELAÇÃO AOS VÍNCULOS E APRENDIZAGEM}

A neuroplasticidade é a capacidade do cérebro humano de mudar suas trajetórias neurais e sinapses com base nas experiências que o indivíduo vai tendo ao longo da vida, porém com modulações. Esta é a base biológica para formação do self , que se molda e se estrutura através das experiências de apego (Costelo, 2013).

A criança, mesmo após o nascimento, continua em formação, desamparada no sentido das novidades do mundo e dependente de um adulto que a cuide. Esta extensa dependência constitui a base da característica humana como ser social. Por outro lado, põe o ser em vantagem como espécie, já que é criada uma rede social, intensa e complexa, que irá colaborar na coordenação das diversas atividades através da comunicação, atenção compartilhada ,ajuda mútua, colaborando para a adaptação e evolução da espécie. É justamente a complexidade da sociedade, com suas diversas atividades e interações, que se explica a evolução de um cérebro tão grande nos seres humanos (Costelo, 2013).

Durante o desenvolvimento fetal acontece a neurogênese, que é a formação de neurônios. Após ao nascimento, até por volta dos dezesseis anos, a ênfase é na sinaptogênese, que consiste na formação ou mudança na força das conexões sinápticas que conectam neurônios nas redes. Há, também, a poda neural, que é a eliminação de neurônios ou sinapses através da morte celular e pela competição com outras sinapses que ocorre mais fortemente nos períodos de rápido desenvolvimento na infância. De acordo com Diamond et. al. (1971), estudos com ratos têm demonstrado que quanto mais estimulados e desafiados são, mais neurônios, conexões sinápticas, vasos sanguíneos e atividade mitocondrial possuem, sugerindo fortemente que isto também ocorre com os humanos. As crianças enriquecem a partir dos estímulos, desafios, impulsionando o cérebro a crescer.

A criança nasce com um cérebro amorfo e pouco formado, o que garante adaptar-se ao grupo social ao qual pertence. As experiências sociais e comunicativas tornam-se parte do sistema nervoso. As características individuais dependem dos desafios e 
oportunidades do meio ambiente imediato, social e físico. Assim, os pais são o primeiro contexto de mundo a que a criança é exposta e que o seu cérebro precisa se adaptar

O bebê é altamente responsivo à interação humana, particularmente nas interações face-a-face que marcam a experiência inicial de apego. Schore (2000) descreve como o "face a face" é altamente excitante e tem um poder de afetar e mobilizar o bebê . Olhares de adoração, de admiração, estimulam a produção de compostos bioquímicos que ajudam o cérebro a crescer.

As experiências de interação, promovem conexões neurais e o cérebro se torna mais ricamente interligado. Assim se desenvolve o cérebro direito, onde reside a sede da sensibilidade que afetará a regulação e os fundamentos da inteligência emocional. É onde os sentimentos são experimentados e onde o comportamento emocional e a capacidade de resposta às pistas dos outros são processados e desenvolvidos. No contexto da relação entre bebê e mãe, ocorre a "dança mútua de responsividade" (Gerhardt 2004, p.31). Isso foi definido como sintonia afetiva e é a experiência central do Apego Seguro. A intensa sensibilidade do adulto à experiência do bebê com o meio ambiente auxilia na regulação do estresse. A presença do adulto é essencial para evitar inundações avassaladoras de experiências emocionais que não podem ser processadas ou contidas nesse estágio do desenvolvimento primitivo do bebê. (Gueddes, 2006)

Comportamentos e experiências repetidas se tornam parte da fiação cerebral, uma vez que o cérebro é moldado através das interações com os outros e dos efeitos que estes têm física e biologicamente durante o desenvolvimento. Tais efeitos são tão profundos que se tornam parte da estruturação humana. Por sua vez, o sistema do cérebro social - estruturas corticais e subcorticais - que irão processar toda informação são responsáveis pela aprendizagem, memória, organização, planejamento e execução (Costelo, 2013).

Através do Sistema Regulatório, que é o responsável pela homeostase interna do corpo, ocorrerá a regulação do metabolismo, secreção hormonal, excitação, sistema 
imunológico, como também a mediação de aproximação, evitação, inibição e respostas de luta/ fuga . O Sistema de Regulação de Estresse (HPA), por sua vez, é o que regula os hormônios envolvidos na resposta corporal do estresse e do medo, e é intensamente influenciado pelas experiências na infância, como o sistema de apego vivenciado, experiências positivas ou adversas, bem como traumas. Portanto, o cérebro é desenvolvido, modificado, "recriado" a partir de experiências sociais e vinculares que desde o início a criança experimenta com os outros. Tudo isto está associado ao afeto, responsividade, empatia e acolhimento ou vivências totalmente adversas e áridas, mas que irão determinar as formas de ser, pensar e agir (Costelo, 2013).

Assim, quando o gerenciamento dos sentimentos é moderado, as funções cerebrais direita e esquerda começam a se integrar. Há uma mudança da dominância do cérebro direito para o lado esquerdo do cérebro que funciona no segundo ano do bebê, à medida que a habilidade linguística se desenvolve. $O$ cérebro esquerdo é especializado em processamento sequencial e verbal e operações de ordem superior. É também onde o sequenciamento de eventos leva ao desenvolvimento de um sentido de narrativa contínua baseado em antes, agora e depois. Como os sentimentos podem ser colocados em palavras, o cérebro direito e esquerdo se torna mais integrados. O hemisfério direito permanece associado a processos inconscientes e afetivos (emocionais) e o hemisfério esquerdo a processos conscientes concretos. Isso tem implicações sobre como o estresse pode ser gerenciado no contexto da sala de aula e sobre a tarefa de aprendizagem. Linguagem e pensamento podem moderar a ansiedade. As atividades que envolvem a função cerebral esquerda podem ajudar a moderar a função cerebral direita super estimulada (Gueddes, 2006).

É importante se ter essas noções quando lidamos com crianças que estão iniciando o domínio da linguagem, bem como com aquelas que já adquiriram esta aptidão e estão vivenciando o desafio de deixar suas figuras primárias de apego e embarcarem na tarefa da aprendizagem. 


\section{PROPOSTA DE INTERVENÇÃO NO CONTEXTO ESCOLAR A PARTIR DAS CONTRIBUIÇÕES DA TEORIA DO APEGO}

Workshop: A vinculação segura como instrumento para o professor em sala de aula procedimentos

A partir do entendimento sobre a importância do investimento na interação segura entre professor e aluno desde a entrada deste na vida escolar, pensou-se na construção de um workshop teórico-vivencial na modalidade de capacitação aos professores de anos iniciais das escolas infantis. Este trabalho estará pautado na promoção de espaços de reflexão e práticas de vinculação segura, a fim de garantir a qualidade no processo ensino-aprendizagem. Pretende-se que este projeto de trabalho seja executado por meio de conteúdos teóricos expositivos e experiências práticas, a fim de instigar meios de reflexão e escuta sobre a importância do vínculo seguro entre cuidador e turma, de forma individual e coletiva, para o asseguramento da continuidade do desenvolvimento do aluno. Entende-se que a construção e manutenção da vinculação segura entre professor e aluno contribui para que este desenvolva estratégias mais seguras nas relações, o que possibilita maior segurança também para a sua apropriação de sua aprendizagem como protagonista do saber, instrumentalizado pela referência que é o professor.

Cabe referir que a proposta de intervenção elaborada pela equipe de profissionais poderá sofrer alterações de acordo com as demandas apresentadas por cada escola e necessidades referidas pelas equipes diretivas de cada instituição. A proposta tem o objetivo de instrumentalizar membros representantes das equipes diretivas e, mais especificamente, os professores que trabalham com anos iniciais nas escolas, através da perspectiva teórica do Apego, proposta por John Bowlby. Nesta estrutura básica, constarão os conteúdos específicos a serem trabalhados com as equipes, além da realização de técnicas vivenciais, a serem avaliadas de acordo com as demandas institucionais, perfil de cada equipe, quantidade de participantes, entre outros aspectos a serem definidos numa primeira reunião a ser previamente agendada com cada escola para a apresentação do trabalho. 


\section{PÚBLICO-ALVO}

Escolas municipais; estaduais e particulares de Educação Infantil. O workshop será realizado com os seguintes profissionais de cada instituição: membros representantes das equipes diretivas e professores de anos escolares iniciais.

\section{JUSTIFICATIVA}

Entende-se que envolver não apenas a direção de cada instituição de ensino, mas também os professores que atuam diretamente com as crianças em início de vida escolar contribuem para a instrumentalização autônoma, além de ampliar a rede de cuidados efetivos, numa proposta de olhar atento às necessidades integrais de cada criança.

\section{DURAÇÃO DO WORKSHOP}

A proposta de intervenção terá a carga horária total de 16 horas, a serem subdivididas de acordo com as possibilidades de cada instituição de ensino. São 4 módulos de 4 horas, ou 8 módulos de 2 horas, podendo ser realizados em 2 dias seguidos, 4 encontros ou mesmo 8 encontros menores.

Para fins de organização escrita e apresentação da proposta de trabalho, será levado em conta a opção de 16 horas divididas em um sábado e domingo - manhã e tarde.

\section{WORKSHOP: ESTRUTURA E PRÁTICA}

Reunião de apresentação para a apresentação do projeto de intervenção e oferecimento do Workshop como serviço, ou seja, a equipe fará uma primeira reunião com os representantes de cada instituição de ensino, após contato prévio e agendamento de horário, com o objetivo de fazer a apresentação do projeto de intervenção, justificando a importância de um olhar atento à construção e manutenção da vinculação segura entre professor $x$ aluno em sala de aula para o desenvolvimento do processo ensino-aprendizagem de forma segura e funcional. 
De acordo com o interesse demonstrado por cada instituição, a equipe fará uma breve anamnese, com perguntas direcionadas a respeito do histórico da instituição, filosofia educacional e concepção teórica utilizada, manejos nos processos de mudança e adaptação, equipe de profissionais, formação dos profissionais, quantidade de alunos por turma, etc. Neste mesmo encontro, poderão ser acessadas informações sobre eventuais conflitos ou limitações da instituição e seus membros, do ponto de vista da direção da escola. Ao final, serão feitas combinações com cada instituição, de modo que a direção possa avaliar a proposta de trabalho e entrar em contato com a equipe para a contratação do serviço.

Primeiro dia: Apresentação da Equipe e do Contrato de Trabalho, onde cada integrante da equipe de formação se apresenta dizendo o seu nome, sua profissão e quais os nossos objetivo e contribuições com este o workshop, explicando também sobre a nossa origem. O Contrato de Trabalho será previamente elaborado pela equipe e entregue a cada participante para que, juntos, seja possível fazer a leitura e, assim, afirmar o compromisso com o final de semana de trabalho a ser desenvolvido de forma conjunta. No Contrato de Trabalho, constará uma breve introdução da Teoria do Apego e da importância da vinculação segura entre cuidador $x$ criança, além de informações a respeito do transcorrer do workshop, com conteúdos teóricos a serem trabalhados, bem como significados atrelados às vivências práticas.

A Teoria do Apego propõe-se a trabalhar com conceitos teóricos e práticos que podem mobilizar de forma profunda (consciente e não-consciente) aspectos emocionais, familiares e históricos dos envolvidos, questões sobre a dinâmica pessoal e a função de cuidador/educador. Como parte do Contrato de Trabalho, é importante criar um ambiente afetivamente seguro e respeitoso entre os profissionais que estarão aplicando as oficinas e a equipe da escola. Ressaltar que será um momento destinado ao encontro das pessoas envolvidas com suas histórias, seus anseios, seus saberes e suas dúvidas profissionais. Também é fundamental o envolvimento e comprometimento com a proposta. Para tanto, após as apresentações coletivas, será importante a equipe perguntar sobre as principais dificuldades do ponto de vista dos participantes e de que maneira estão trabalhando como forma de complementar a 
visão da direção na reunião de apresentação do trabalho, e envolvê-los nas possibilidades de auxílio que a Teoria do Apego tende a oferecer para problemas encontrados no cotidiano escolar.

Como parte da acolhida inicial, cada participante receberá outra folha, com uma atividade intitulada Como cheguei aqui? contendo diversificadas palavras que denotam sentimentos e emoções que poderiam vir a caracterizar a forma como cada um chegou no que tange aos aspectos emocionais para o primeiro dia do workshop. Esta atividade investiga questões de medo, angústias, inseguranças, dificuldades, perspectivas, ideias, planos, à medida que cada participante deverá circular as palavras com as quais mais se identificar. Esta atividade poderá ser aproveitada para uma reflexão conjunta e compartilhamento de experiências prévias no contexto escolar e no dia-a-dia.

Apresentação coletiva dos participantes: Este momento será realizado a partir de uma atividade chamada Dinâmica da Entrevista. A equipe solicitará que os participantes se separem em duplas, priorizando a escolha de alguém para formar a dupla que menos tenha contato no dia-a-dia. A proposta é de que um dos membros da dupla de cada vez faça perguntas ao outro, de forma a conhecê-lo em diferentes aspectos da vida, dentro e fora do ambiente escolar, para depois poder apresentá-lo aos demais participantes, de forma coletiva. O mesmo será feito após, com o participante que foi entrevistado, onde este assume o papel de entrevistador para colher informações a respeito do outro. As perguntas a serem feitas ficarão a cargo dos próprios participantes. Isto também será trabalhado posteriormente, entendendo os limites de cada um na aproximação do outro. Após, cada dupla fará a sua apresentação para o grande grupo e, ao final de todas as apresentações, a equipe instigará determinadas reflexões sobre a importância de conhecer o outro, sua história, sua forma de ser para além daquilo que aparece a cada dia, bem como a eficácia da escuta ativa durante a aproximação com as coisas que o outro expõe numa proposta de confiança.

Atividade do Escudo - Cuidando do cuidador: Nesta dinâmica será realizada uma espécie de passeio pela história da vida de cada participante, pelo seu sistema ecossocioemocional. Esse sistema se refere à família, ao qual se viveu as primeiras 
relações de amor, aprendizados e de apego. Será solicitado que todos se acomodam em seus lugares de uma forma confortável, se quiserem deitar também é possível. Nesse momento orienta-se para que fechem os olhos, respiram fundo e a equipe explica que será realizada uma espécie de "viagem" para cada etapa da vida: a infância inicialmente e depois a vida adulta. A equipe conduzirá os participantes que, de acordo com o que for sendo falado sobre as cenas, cada um terá suas memórias e irá dando nome para cenas, conforme explicado. No término da memorização, cada participante irá receber um escudo de autoconhecimento, que tem lugar para seis cenas. A tarefa será desenhar as cenas e nomeá-las. O objetivo dessa prática se refere a uma busca interior, a fim de que cada um consiga compreender como se tornou ele mesmo, construiu sua subjetividade, consciência, seu eu, usando os conceitos de apego. Com isso o professor pode perceber como foram significativas suas relações primárias, o quanto elas interferem atualmente na sua vida adulta e a importância de se sentir seguros na infância. Será possível compreender a dimensão do cuidador ser alguém que acolhe, proporcionando um vínculo de amor, proteção, tornando-se a base e o porto seguro na relação. O professor ao refletir sobre suas vivências e cuidados na infância, pode conseguir pensar em outras maneiras de trabalhar com seus alunos e inclusive se for o caso ressignificar sua forma de atuar.

Introdução à Teoria do Apego e Importância da Vinculação Segura: Este momento será teórico. Iniciaremos com uma breve apresentação da Teoria do Apego e suas origens: Quem foi John Bowlby e seus principais colaboradores, breve contextualização do momento histórico da teoria, desenvolvimento da psicologia e psicanálise em que a teoria se desenvolveu, etologia e demais fatores de influência. Discutiremos sobre a importância dos vínculos afetivos para o desenvolvimento do ser humano e da segurança afetiva para a exploração do mundo. Neste momento iniciaremos a conceitualização dos sistemas de apego, de cuidado e de exploração, a partir de análises etológicas e de sobrevivência da espécie humana.

Passaremos então o vídeo Experimento com Macacos, que constitui uma ferramenta para refletir sobre a importância do vínculo seguro nos processos de exploração do mundo. Refletiremos sobre os efeitos das aprendizagens da criança no contexto 
familiar e suas formas de expressão no ambiente escolar. A partir do vídeo Experimento com Macacos, é possível reforçar a reflexão a respeito da importância da proximidade e da comunicação clara e não-violenta entre professor e aluno, a fim de assegurar diferentes possibilidades de aprender. Além disso, instigar para que estejam atentos às autorizações para a exploração das crianças, para que estas não entendam e associem que explorações podem ser perigosas e causar danos, assim como mostra o vídeo, enfatizando, desta forma, a importância de uma referência segura para a criança explorar o mundo ao seu redor; o que consiste na organização e estruturação para um desenvolvimento saudável.

Introdução à Teoria do Apego e Importância da Vinculação Segura: Para adentrar aos aspectos primeiros da Teoria do Apego, realizaremos uma atividade denominada Dinâmica do João Bobo, cujas compreensões grupais a partir da atividade serão resgatadas pela equipe em diferentes momentos do conteúdo teórico posterior. Esta vivência tem por finalidade demonstrar questões relacionadas a confiança em si mesmo e no outro em situações de instabilidade e ameaça de perda de controle. Acionam mecanismos instintivos de proteção e defesa diante de circunstâncias que demandam emocionalmente. Também reflete sobre a dinâmica cuidador $\mathrm{x}$ pessoa cuidada, podendo ser associada à prática escolar enquanto o papel do educador nas práticas do cuidado com cada aluno. A equipe, portanto, solicitará que o grupo se divida em trios, de forma que um dos membros seja elegido para ficar no meio e ser o João Bobo, e terá os seus olhos fechados e vedados, os pés juntos ao chão, enquanto os outros dois membros balanceiam o seu corpo para frente e para trás. Todos os participantes do trio passarão pela mesma experiência, na medida em que a equipe sinalizar a troca. Após todos os participantes terem realizado a atividade, será feito um momento reflexivo de partilha com o grande grupo a respeito das impressões, sensações e representações acerca da atividade. Esta também será a porta de entrada para o acesso aos conteúdos teóricos a seguir, que serão apresentados por projeção em slides.

Estilos de Apego: Será possível retomar os conteúdos teóricos iniciados com a exposição do vídeo Teste da Situação Estranha e, a partir disso, refletir sobre 
pensamentos e emoções associados ao teste, bem como às formas de agir no contexto diário, considerando a prática do educador. $\mathrm{O}$ vídeo oportuniza a equipe a adentrar aos modelos vinculares disponíveis a partir da experiência do próprio cuidador. Logo, pode ser uma espécie de acesso à compreensão e identificação dos tipos de apego aprendidos no início da vida e à influência exercida por eles nas formas como cada participante enxerga a si mesmo, as pessoas e o mundo, e sobre os efeitos gerados na relação estabelecida com os pares, tanto na dinâmica do cuidar, quanto na possibilidade de ser cuidado.

Segundo dia - Resgate das aprendizagens do dia anterior sob a forma de tópicos e acolhimento das dúvidas que possam ter permanecido no grupo. A equipe solicita para os participantes que expressem suas dúvidas sobre o conteúdo estudado, as quais serão anotadas em itens, para na sequência serem respondidas pela equipe. A ideia é que eles possam se sentir à vontade para expor suas dúvidas e que a equipe possa ressaltar aos participantes sobre a importância deste espaço, destinado para esclarecimento de conteúdos que por algum motivo possam não ter assimilado, até mesmo em função da complexidade dos assuntos.

Construções práticas a partir da teoria: A partir das reflexões possíveis sobre a teoria e os vídeos mostrados, a equipe solicitará que o grande grupo se divida em subgrupos, de acordo com a quantidade de participantes, e que juntos possam elaborar práticas criativas que estejam direcionadas a impulsionar os alunos para a exploração sem medo ou que entendam que possam pedir ajuda sempre que necessário. As práticas podem ser em formato de atividades criativas, lúdicas, e deverão ser escritas, a fim de que, ao final, possam ser feitas trocas entre os subgrupos e todos possam ter as ideias de cada um para a sua prática escolar posteriormente. A proposta é de que cada participante, nos seus subgrupos, e em conjunto com outras ideias, possa elaborar atividades de interação que possam, ou não, envolver conteúdos curriculares. As estratégias e processos de adaptação e acolhimento dos alunos no início do ano escolar (sejam alunos novos ou alunos que já frequentavam a escola) serão um tema estimulado por nós. Após, os subgrupos serão convidados a apresentarem suas atividades ao grande grupo. 
Dinâmica para auto reflexão e potencialização dos recursos do professor: Para este momento pensamos em 2 possibilidades de dinâmicas que serão escolhidas de acordo com o perfil do grupo e demandas da instituição: a) Desenho do lugar seguro: Nessa atividade será solicitado que cada professor desenhe em uma folha, um lugar ao qual se sentia seguro em sua infância e também o nome que costumavam chamálo. Em seguida no verso da folha irão desenhar um lugar em que se sente seguro no momento atual e o nome que o chamam. Na sequência, será aberto um espaço para quem quiser comentar sobre seus desenhos. Essa dinâmica pode ajudá-los na busca de lembranças significativas, resgate de memórias que proporcionaram conforto, segurança, proteção, sendo um lugar que de alguma maneira proporcionou e proporciona acolhimento. Que sensação o professor sentiu ao se recordar de seu lugar seguro, que representação esse lugar tem hoje em sua vida. Ao refletir sobre isso, poder pensar na importância da construção de laços afetivos seguros e contínuos. Esse vínculo de asseguramento promove autoconfiança na criança, que forma sua auto imagem ao internalizar essas relações estabelecidas. O Objetivo é de promover reflexão e tomada de consciência sobre potencialidades e dificuldades de cada um. Entrar em contato com esse lugar seguro, ao qual se sentiam e sentem-se amparados em suas angústias, é auxiliar o professor na possibilidade de poder compreender a relevância de proporcionar um espaço acolhedor ao seu aluno. Caso esse aluno não tenha aprendido estratégias mais seguras em seu ambiente familiar, através de suas relações primárias, ele pode conseguir desenvolver na escola, se caso o professor que é sua figura de referência no ambiente escolar permitir um ambiente seguro, através de suas relações em sala de aula. Não temos intenção de descobrir o padrão de apego de cada um, pois acreditamos que para tanto seria necessário um acompanhamento maior. b) Dinâmica kit de primeiros socorros: Nessa atividade cada professor vai receber da equipe um desenho de uma mala. Nessa mala cada um irá colocar o que o ajuda quando não está bem, como também o que não o ajuda quando não está bem. Posterior a atividade, será aberto para quem quiser e se sentir à vontade, falar sobre o que colocou em sua mala. $O$ objetivo da atividade é o de cuidar do professor, aceitá-lo em suas dificuldades, apoiá-lo nas suas potencialidades, que ele possa se sentir acolhido e respeitado. Assim também acontece com a criança, que necessita ser aceita, validada em suas potencialidades 
e respeitada em suas individualidades. Sendo assim a proposta desta dinâmica é proporcionar aos professores um espaço para troca de recursos, ao qual terão a oportunidade, de serem acolhidos em suas demandas e cuidados, como também de fazer uma autoavaliação de sua conduta em sala de aula. É possível trabalhar a empatia, para que eles possam tentar compreender, que em algum momento, o que é de certa forma bom para o professor, pode não ser para o aluno. Assim como os professores precisam ser compreendidos dentro de suas inseguranças e dificuldades, os alunos também necessitam desse amparo. É o vínculo afetivo, com base em uma relação vincular de confiança entre professor e aluno que vai corroborar no processo de exploração e aprendizado.

Acompanhamento e Supervisão de Casos de Alunos: Neste último momento do encontro, iremos trabalhar com os professores casos de alunos do presente e do passado, buscando novas compreensões e possibilidades de intervenção. Podemos pedir que a equipe escolha um caso, faremos perguntas que ajudem a direcionar o olhar e pediremos ao grupo que contribua com sua compreensão. Discutiremos também possíveis estratégias e estimularemos os professores trocarem estratégias entre si, numa tentativa de fortalecer a rede de apoio da equipe, tão importante quando lidamos com alunos difíceis. Se não for possível trazer casos reais da escola, nós também podemos trazer casos fictícios para essa reflexão, como segunda proposta para estudo.

Essa é uma estrutura de intervenção a partir da qual elaboramos nossa prática de formação de professores. De acordo com as demandas específicas de cada instituição escolar, podemos substituir algumas atividades por outras, focando temas que vão de encontro às necessidades. Desta forma, podemos reforçar outros temas, tais como: estratégias de intervenção baseadas na TA utilizadas na escola; dinâmicas de apego aparecendo no cotidiano escolar; adaptação; processos de ensino aprendizagem; relação com a aprendizagem; estruturação do espaço escolar; organização de rotina dos grupos, entre outros. 


\section{PLANO DE ACOMPANHAMENTO}

Após a realização do workshop, a equipe de profissionais, em acordo com cada instituição de ensino, retorna depois de um mês para visitar e verificar como a escola e os professores estão manejando e pondo em prática as estratégias que aprenderam. O objetivo deste acompanhamento é o de oferecer suporte para a escola, a fim de acolher as dúvidas que vão surgindo com a prática ampliada do contexto escolar. Pode-se, neste momento, verificar com a equipe o que já fazem para promover situações de segurança na ambiente escola, que estratégias estão usando e sugerir outras ferramentas, se necessário. Como alternativa complementar e, de acordo com o que a equipe de profissionais que estiverem fazendo a visita observar em relação às práticas escolares, pode-se promover um novo momento de encontro com os professores, a fim de fornecer escuta ativa e instrumentalização por meio de sugestões práticas quanto a atividades e dinâmicas. O mesmo pode ser feito em relação à direção (num segundo momento), a fim de verificar a efetividade da proposta de intervenção realizada.

\section{CONSIDERAÇÕES FINAIS}

Entende-se que este projeto pode corroborar para que as escolas possam aderir a estratégias mais seguras na forma de relacionamentos entre professores e alunos, usando do acolhimento e do cuidado para promover o aprendizado. A escola é um dos primeiros agentes socializadores, depois que a criança sai de seu aconchego familiar e da sua relação primária com seus pais. Ela irá formar seus modelos operativos internos (MOI) com base nessas relações e experiências que irá internalizar com sua figura de apego. Desta forma a criança desenvolve a percepção que terá sobre si, os outros e o mundo. Quando a criança entra no contexto escolar, ela vai ampliar seu mundo, desenvolvendo a socialização com seus pares, seus professores e descobrindo seus limites. O professor pode servir como um modelo a ser seguido pelo aluno, ele representa a figura de cuidado alternativa, importante para o desenvolvimento saudável e funcional da criança. Pode inclusive, auxiliar a criança para desenvolver estratégias de comportamentos mais seguras, caso não tenha 
desenvolvido em suas relações primárias com seus pais. $O$ vínculo seguro desenvolvido na relação de professor e aluno pode permitir que a criança tenha uma relação mais assegurada com o mundo externo, sendo essencial para que se sintam capazes e seguros. O papel do educador atualmente não é mais o de único saber e de apenas repassar conteúdos, mas sim representa uma figura importante para o desenvolvimento infantil. Ao acolher, ouvir, dar voz e vez ao seu aluno, o professor não só ensina como também pode estimulá-lo em suas potencialidades, para no futuro serem adultos com estratégias de comportamentos mais seguras.

Nesta proposta de intervenção, pretende-se ouvir do professor, como é seu trabalho e dentro do que este apresentar sobre sua experiência poder, se for o caso, ajudá-lo a ressignificar atitudes, para que possa construir com seu aluno um vínculo com base em uma relação de confiança. Essa nova compreensão e autoavaliação que cada professor poderá realizar, será possível através da teoria apresentada, explicando sobre os conceitos da teoria do apego de Bowlby. É importante salientar que a ideia da proposta não é fazer com que o professor aprenda todos os conceitos e estilos de apego, pois seria muito complexo, dentro desse tempo em que será realizado o workshop. O objetivo é o de ajudá-lo a compreender a importância de construir um vínculo seguro com o aluno, entendendo o quanto isso implica na sua aprendizagem e na forma que ele irá perceber o mundo.

As atividades propostas, permitem ao professor entrar em contato com suas relações primárias, suas inseguranças, medos, dificuldades ou até mesmo potencialidades. Ao permitir-se refletir sobre a importância que a sua figura de cuidado e proteção teve em sua infância, aprendendo através dela a perceber e avaliar o mundo, é possível pensar na relevância que isso tem para o aluno em sala de aula. A criança aprende, é acolhida e validada em suas explorações, quando entende que tem no professor seu porto seguro.

\section{REFERÊNCIAS}

Amado, J.; Freire, I.; Carvalho, E.; André, M. J. (2009). O lugar da afectividade na relação pedagógica: contributos para a formação de professores. Sísifo - Revista de 
Ciências da Educação. $\quad$ N. $8 . \quad$ Disponível em https://www.researchgate.net/profile/lsabel_Freire3/publication/28320319_O_lugar_d a_afectividade_na_Relacao_Pedagogica_Contributos_para_a_Formacao_de_Profes sores/links/544050360cf2fd72f99dd589/O-lugar-da-afectividade-na-RelacaoPedagogica-Contributos-para-a-Formacao-de-Professores.pdf

Araújo, U. F. (1996). O ambiente escolar e o desenvolvimento do juízo moral infantil. In Cinco Estudos de Educação Moral. Casa do Psicólogo. São Paulo.

Belotti, S.H.A. De Faria, M.A. Relação professor/aluno. (2010). Revista eletrônica Saberes da Educação. Vol 1, no 1. Disponível em: http://docs.uninove.br/arte/fac/publicacoes/pdfs/salua.pdf - Acesso em 25 de outubro de 2017.

Bowlby, J. (1989). Uma base segura: Aplicações clínicas da teoria do apego. Porto Alegre: Artes Médicas.

Casellato, G. (2012). Bulling Escolar: onde mora o perigo? Uma reflexão com base na Teoria do Apego sobre a dinâmica agressor/agredido. O mundo da saúde. São Paulo.

Costello, P.C. (2013). Attachment- Based Psychoterapy Helping Patients Develop Adaptive Capacities. APA.

Dalbem, J. X.; Dell'Aglio, D. D. (2005). Teoria do apego: bases conceituais e desenvolvimento dos modelos internos de funcionamento. Arq. bras. psicol. v.57 n.1 Rio de Janeiro. Disponível em: http://pepsic.bvsalud.org/scielo.php?script=sci_arttext\&pid=S180952672005000100003

De La Taille, Y. (1998). Limites: três dimensões educacionais. Editora Ática. São Paulo.

Estrela, M. T. (2002). Relação Pedagógica, Disciplina e Indisciplina na Aula. Porto: Porto Editora. 
Ferraz, R.D.C.S.N. Ristum, M. A. (2012). Violência psicológica na relação entre professor e aluno com dificuldades de aprendizagem. Psicol. educ. no.34 São Paulo.

http://pepsic.bvsalud.org/scielo.php?script=sci_arttext\&pid=S1414-

69752012000100007 - Acesso em 20 de outubro de 2017.

Freddo, T. M. (2004). Um olhar, pela dimensão afetiva, sobre o sujeito que aprende: vínculos e afeto em consonância com a aprendizagem escolar. Universidade de Passo Fundo. Disponível em: http://docplayer.com.br/11124460-Um-olhar-pela-dimensaoafetiva-sobre-o-sujeito-que-apreende-vinculos-e-afeto-em-consonancia-com-aaprendizagem-escolar.html

Geddes, H. (2006). Attachment in the Classroom.Worth Publishing LTD..

Krueger, M.F. (2003). A relevância da afetividade na educação infantil. Instituto Catarinense de pós-graduação. Disponível em www.posuniasselvi.com.br/artigos/rev03-04.pdf - Acesso em 31 de outubro de 2017.

Yalom, I. \& Leszcz, M. (2005). The theory and practice of group psychotherapy. New York: Basic Books.

. (1997). Parâmetros curriculares nacionais: Introdução aos parâmetros curriculares nacionais / Secretaria de Educação Fundamental. - Brasília : MEC/SEF.

Parolin, I. C. H \&Küster, S.M.G. S (2010). As Emoções e os Estilos de Aprendizagem no Processo de Ensinar/Aprender.

Piaget, J. (1996). Os Procedimentos da Educação Moral. In Cinco Estudos de Educação Moral. Casa do Psicólogo. São Paulo.

Ribas, A. F. P. \& Moura, M. L. S. (2004). Responsividade Materna e Teoria do Apego: Uma Discussão Crítica do Papel de Estudos Transculturais. Universidade do Estado do Rio de Janeiro. Disponível em: http://www.scielo.br/pdf/\%0D/prc/v17n3/a04v17n3.pdf. 
Rosa, R.; Martins, F. E.; Gasperi, B. L.; Monticelli, M.; Siebert, E. R. C.; Martins, N. M. (2010). Mãe e filho: os primeiros laços de aproximação. Ver. Enferm. Disponível em: http://www.scielo.br/pdf/ean/v14n1/v14n1a16

Tassoni, E.C.M. (2000). Afetividade e aprendizagem: a relação professor-aluno. Universidade Estadual de Campinas e Escola Comunitária de Campinas. Disponível em:

https://s3.amazonaws.com/academia.edu.documents/44850674/ANPEd_2000.pdf?A WSAccessKeyld=AKIAIWOWYYGZ2Y53UL3A\&Expires $=1509112703 \&$ Signature $=W$ efLsEMSvhDd8Tj1Bkg1RQGTJSU\%3D\&response-content disposition=inline\%3B\%20filename\%3DAFETIVIDADE_E_APRENDIZAGEM_A_REL ACAO_PRO.pdf acesso em 27 outubro de 2017.

Enviado: Setembro, 2018

Aprovado: Outubro, 2018 